OPEN ACCESS

Edited by: Isidro Ferrer, University of Barcelona, Spain

Reviewed by: Andrea Fuso, Sapienza University of Rome, Italy Reinald Pamplona, University of Lleida, Spain

*Correspondence:

A. Veronica Witte, Department of Neurology, Max Planck Institute for Human Cognitive and Brain Sciences, Stephanstraße 1A, 04103 Leipzig,

Germany

witte@cbs.mpg.de

Received: 20 May 2015 Accepted: 26 June 2015

Published: 08 July 2015

Citation:

Huhn S, Kharabian Masouleh S, Stumvoll M, Villringer $A$ and Witte AV (2015) Components of a Mediterranean diet and their impact on cognitive functions in aging.

Front. Aging Neurosci. 7:132. doi: 10.3389/fnagi.2015.00132

\section{Components of a Mediterranean diet and their impact on cognitive functions in aging}

\author{
Sebastian Huhn ${ }^{1}$, Shahrzad Kharabian Masouleh ${ }^{1}$, Michael Stumvoll2,3, Arno Villringer ${ }^{1,2}$ \\ and A. Veronica Witte ${ }^{1,2 *}$

\begin{abstract}
1 Department of Neurology, Max Planck Institute for Human Cognitive and Brain Sciences, Leipzig, Germany, ${ }^{2}$ Collaborative Research Centre 1052 'Obesity Mechanisms', Subproject A1, Faculty of Medicine, University of Leipzig, Leipzig, Germany,
\end{abstract} \\ ${ }^{3}$ IFB Adiposity Diseases, University of Leipzig, Leipzig, Germany
}

Background: Adhering to the Mediterranean diet (MeDi) is known to be beneficial with regard to many age-associated diseases including cardiovascular diseases and type 2 diabetes. Recent studies also suggest an impact on cognition and brain structure, and increasing effort is made to track effects down to single nutrients.

Aims: We aimed to review whether two MeDi components, i.e., long-chain omega-3 fatty acids (LC-n3-FA) derived from sea-fish, and plant polyphenols including resveratrol (RSV), exert positive effects on brain health in aging.

Content: We summarized health benefits associated with the MeDi and evaluated available studies on the effect of (1) fish-consumption and LC-n3-FA supplementation as well as (2) diet-derived or supplementary polyphenols such as RSV, on cognitive performance and brain structure in animal models and human studies. Also, we discussed possible underlying mechanisms.

Conclusion: A majority of available studies suggest that consumption of LC-n3-FA with fish or fishoil-supplements exerts positive effects on brain health and cognition in older humans. However, more large-scale randomized controlled trials are needed to draw definite recommendations. Considering polyphenols and RSV, only few controlled studies are available to date, yet the evidence based on animal research and first interventional human trials is promising and warrants further investigation. In addition, the concept of food synergy within the MeDi encourages future trials that evaluate the impact of comprehensive lifestyle patterns to help maintaining cognitive functions into old age.

Keywords: cognition, plasticity, omega-3 fatty acids, polyphenols, resveratrol, memory, brain structure

\section{Background: Health Benefits of the Mediterranean Diet}

According to the "Global Strategy on Diet, Physical Activity and Health", a review developed by the World Health Organization (WHO), the Mediterranean Diet (MeDi) is a promising strategy to prevent from diseases and enhance quality of life (World Health Organization, 2009). The review aims specifically on interventions, that reduce the risk for non-communicable diseases like cerebro- and cardiovascular diseases, cancer, respiratory diseases, diabetes and neurodegenerative 
diseases, which comprise the leading causes of death worldwide (World Health Organization, 2009). The MeDi was first investigated by Ancel Keys in the 1950s during his Seven Countries Study, a large-scale prospective cohort-study with more than 11,000 participants (Keys, 1970; Keys et al., 1986). Keys et al. (1986) observed a considerable difference in the eating pattern of Southern European countries, compared to Northern Europe and the USA. This Mediterranean eating pattern and related low intake percentage of total energy from saturated fatty acids correlated with lower serum cholesterol and lower blood pressure in Mediterranean countries, which were again associated with a lower coronary mortality and a lower risk for the above mentioned diseases in comparison to countries adhering to a Western-type diet (Keys et al., 1986).

Distinctive for the MeDi is the high consumption of fruits, vegetables, grains as well as sea-fish on regular basis, while the intake of meat and dairy products, just as sweets and convenience food is rather low (Trichopoulou et al., 1995; Gotsis et al., 2015). In addition, the regular consumption of red wine (mainly served with food) and olive oil (as principal source of fat) is characteristic for the MeDi (Willett et al., 1995). For a detailed description of the MeDi, often displayed as food pyramid, see Bach-Faig et al. (2011).

Over the last decades, epidemiologic studies supported and extended Keys' findings to a multitude of health benefits that are provided by the $\mathrm{MeDi}$, e.g., with regard to cancer and cardiovascular diseases (Couto et al., 2011; Lopez-Garcia et al., 2014; Gotsis et al., 2015). More recently, research also focused on neurodegenerative diseases and the impact of MeDi on cognition. For reviews, see e.g., Lourida et al. (2013) and van de Rest et al. (2015). For example, Scarmeas et al. (2006) observed in a prospective cohort of 2258 community-based non-demented individuals that higher adherence to the MeDi is associated with a significant reduction in the risk for Alzheimer's disease (AD). In a systematic review, Lourida et al. (2013) described a reasonably consistent pattern of associations between adherence to the MeDi and related lower risks for $\mathrm{AD}$, reduced rates of cognitive decline as well as better cognitive function. Most recently, Valls-Pedret et al. (2015) described positive results of a long-term randomized clinical trial (RCT) in 334 participants with high cardiovascular risk at a mean age of 67 years (PREDIMED study), providing an even stronger level of scientific evidence than results based on observational studies (Valls-Pedret and Ros, 2013): Here, a MeDi supplemented with either olive oil or nuts, in comparison to a control diet, was associated with improved cognitive functions at 4-year follow-up (Valls-Pedret et al., 2015).

These beneficial effects might be due to multiple biological mechanisms, such as lower concentrations of serum-cholesterol in Mediterranean areas and a related decrease of cardiovascular risk, which were among the first findings by Keys et al. (1986). More specifically, adherence to the MeDi is associated with a reduced risk for coronary heart diseases and metabolic syndrome including hypertension and dyslipidemia, which have been associated with the development of cognitive impairments (for review see e.g., van den Berg et al., 2009; Yates et al., 2012). Additionally, adhering to the MeDi might prevent from disturbances in insulin/glucose metabolism that can result in type 2-diabetes mellitus (DM-2), which is associated with an increased risk for $\mathrm{AD}$ and cognitive impairments (Biessels et al., 2006; $\mathrm{Hu}$ et al., 2013). Even in the absence of manifest DM-2, chronically elevated levels of blood-glucose have shown to exert negative effects on $\mathrm{AD}$ risk and memory performance in older adults (Crane et al., 2013; Kerti et al., 2013).

In sum, the MeDi has been shown to exert positive effects on risk for $\mathrm{AD}$ and cognitive functions during aging, which is probably mediated through reductions in vascular risk factors and benefits on lipid and glucose metabolism. Moreover, based on animal research it has been postulated that specific nutrients could exert even more directly protective effects on the aging brain, e.g., considering amyloid-beta metabolism (Allès et al., 2012). As the MeDi is a complex eating pattern, though, a multitude of single components could cause beneficial effects (Jacobs et al., 2009; Gotsis et al., 2015). Understanding these underlying mechanisms and eventually develop preventive and therapeutic strategies based on those insights, are important issues for future research.

This review aims to evaluate recent findings concerning the effects of single components of the MeDi and their impact on cognition. Firstly, we focus on long chain omega-3 fatty acids (LC-n3-FA) derived from fish, as they distinguish the MeDi from other diets and are consumed with high frequency (Tangney et al., 2014). Secondly, our focus is on plant polyphenols (including resveratrol), which occur mainly in fruit, tea and red wine (Manach et al., 2004). The deliberate consumption of red wine is a well-known feature of the MeDi and especially resveratrol is assigned beneficial effects with regard to overall health, as well as cognition (Baur and Sinclair, 2006; Witte et al., 2014). Both nutrients attracted increasing research interest in the last years.

\section{Impact of Omega-3 Fatty Acids on the Brain}

One characteristic of the MeDi is a high intake of unsaturated fatty acids, including the long-chain omega-3 polyunsaturated fatty acids (LC-n3-FA) eicosapentaenoic acid (EPA, C20:5, n-3) and docosahexaenoic acid (DHA, C22:6, n-3; Figure 1). The main source of DHA and EPA in the human diet is fatty sea fish like mackerels or salmon (Max Rubner-Institut, 2011). DHA and EPA cannot be efficiently synthesized by human enzymes and are therefore regarded as semi-essential (Burdge and Calder, 2005; Burdge, 2006; Sala-Vila and Ros, 2011). Astrocytes in the brain are a major site for the processing of LC-n3-FA. They elongate and desaturate precursor fatty acids such as linoleic acid and the vegetable LC-n3-FA alpha-linolenic acid (ALA) to form EPA and DHA (Moore et al., 1991). Notably, not only the absolute amount of DHA and EPA might be important, but also the ratio of the precursors, as with different precursor ratios, different conversion rates to DHA and EPA occur (Kaur et al., 2014). In addition, intake of ALA, contained e.g., in nuts, might also directly contribute to the beneficial effects of the MeDi on cognition (Blondeau et al., 2009; Valls-Pedret et al., 2015; for a detailed discussion of possibly distinct effects of ALA, EPA and DHA please see Freemantle et al., 2006). 


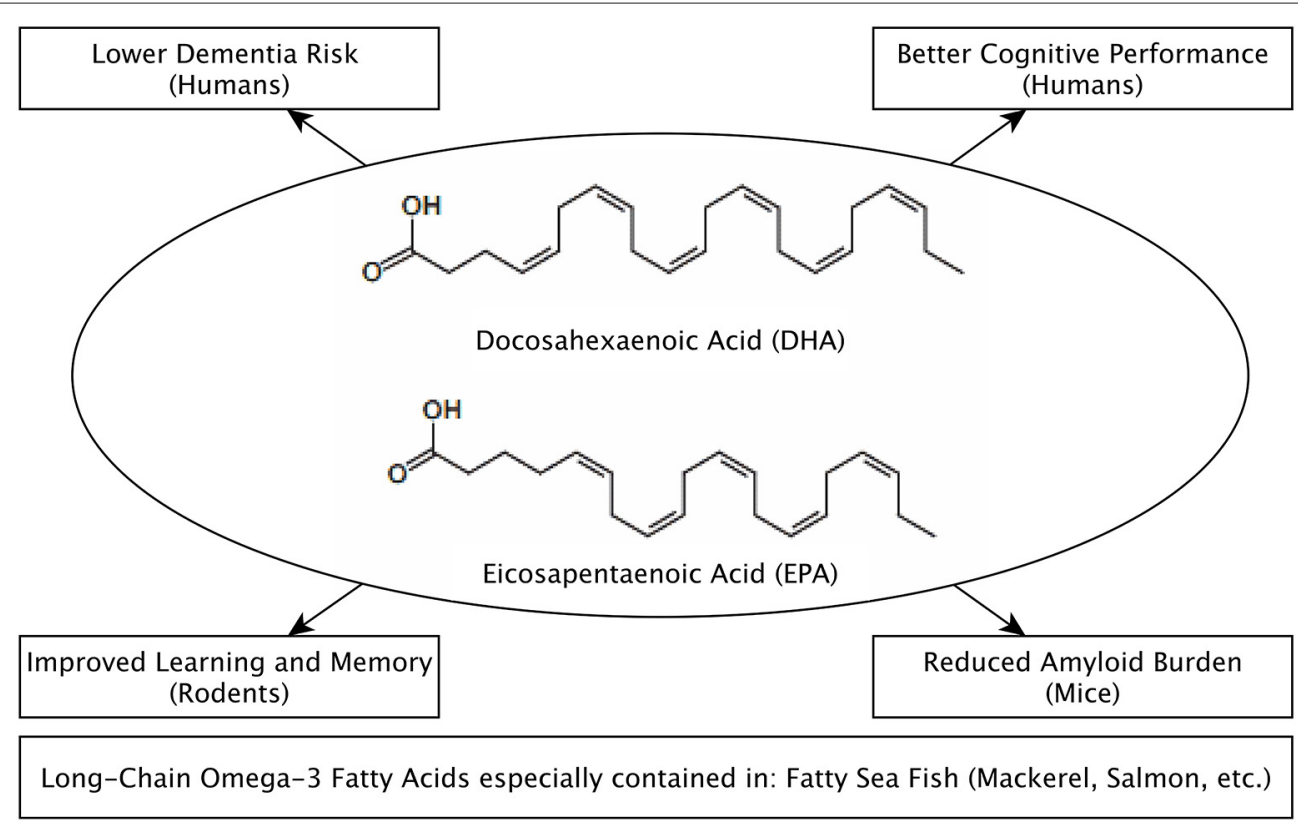

FIGURE 1 | Postulated effects of long-chain Omega-3 Fatty Acids (Eicosapentaenoic Acid, EPA and Docosahexaenoic Acid, DHA) with regard to brain health and their main dietary sources.

It is widely accepted, that LC-n3-FA are crucial for the growth and development of the infant brain during pregnancy and after birth (Kris-Etherton et al., 2009). The predominant LC-n3-FA DHA alone comprises $10-20 \%$ of total fatty acids of the brain and is thought to be important with regard to neuronal differentiation, synaptogenesis, and synaptic function (McNamara and Carlson, 2006). It has also been proposed that the access to DHA during hominid evolution played a key role in increasing the brain to body-mass ratio (Crawford et al., 1999, 2013). However, due to the easy availability of processed food in Western societies today, the consumption of saturated fatty acids and trans-fatty acids increased, while that of DHA decreased. This has been speculated to contribute to an increased incidence of brain disorders such as major depression (Su et al., 2003).

Considering the abundance of DHA in brain tissue and its importance for brain development and evolution, it is reasonable to suppose that DHA also contributes to the evolvement and maintenance of proper cognitive functioning in later life (Gómez-Pinilla, 2008). Indeed, several experimental animal studies demonstrated superior learning and better memory performance in rodents that received supplementary DHA with their diet (Morris et al., 2005). DHA might have a beneficial impact even during pathological conditions like AD. Lim et al. (2005) found in aged mice on a DHA-enriched diet a significant reduction of total amyloid $\beta$ (A- $\beta$ ) by more than $70 \%$ when compared with low-DHA or control chow diets. This could be neuroprotective, given the probable downstream toxicity of $A-\beta$ deposition and its implications in the development of AD (Lim et al., 2005). That is a further finding on the protective properties of DHA against synaptic loss, which is a critical issue in concerns of $\mathrm{AD}$ and seems to support the hypothesis that DHA is protective against $\mathrm{AD}$ (Calon et al., 2004).

These findings are in line with human epidemiological studies that report associations between the consumption of fish in general (Barberger-Gateau et al., 2005; Morris et al., 2005), as well as LC-n3-FA e.g., as dietary fishoil supplement (McCann and Ames, 2005; Gómez-Pinilla, 2008), with better cognitive performances and lower risk of dementia (for a review, see Fotuhi et al., 2009). For example, a large-scale prospective cohort study with 6158 residents of a community in Chicago of 65 years and older, estimated that fish consumption was associated with slower cognitive decline with age, assessed using a global cognitive score (Morris et al., 2005).

The evidence for positive effects of LC-n3-FA fishoil supplementation on cognitive functions in normal and pathological aging based on placebo-controlled RCTs is less clear, see Table 1 for an overview. In an early double-blind RCT in 204 AD patients, Freund-Levi et al. (2006) observed positive effects of LC-n3-FA in a small group of those with very mild $\mathrm{AD}$ who took supplementary LC-n3-FA over 6 months. These findings are in line with a 24-week RCT by Chiu et al. (2008) in 46 participants. Here the authors also concluded that LC-n3-FA improved general clinical function in patients with mild or moderate $\mathrm{AD}$, as well as mild cognitive impairment (Chiu et al., 2008). In an own double-blind prospective interventional study, it was shown that LC-n3-FA improved executive functions and gray matter volume, as well as white matter microstructure in healthy older individuals, after 26 weeks of fish oil supplementation (Witte et al., 2013). Yurko-Mauro et al. (2010) observed in another RCT with 485 healthy subjects older than 55 years that 24 weeks of 
TABLE 1 | Characteristics of studies reporting associations between fish-consumption or LC-n3-FA-supplementation and cognition.

\begin{tabular}{|c|c|c|c|c|c|c|c|c|c|}
\hline \multirow{2}{*}{$\begin{array}{l}\text { Author (year) } \\
\text { Chiu et al. } \\
\text { (2008) }\end{array}$} & \multicolumn{2}{|c|}{$\begin{array}{c}\text { Participants } \\
\text { sample size/age (years) }\end{array}$} & \multirow{2}{*}{$\begin{array}{l}\text { Duration } \\
24 \text { weeks }\end{array}$} & \multicolumn{2}{|c|}{ Intervention } & \multicolumn{2}{|c|}{ Measured outcome } & \multicolumn{2}{|l|}{ Results } \\
\hline & $\begin{array}{l}N=46 \\
\text { memory } \\
\text { complaints }\end{array}$ & $\begin{array}{l}\text { I: } 74.0 \\
\text { (70.1-77.8) } \\
\text { P: } 76.5 \\
(71.8-81.1)\end{array}$ & & $\begin{array}{l}1.8 \mathrm{~g} \\
\text { Omega-3 } \\
\text { PUFAs/d }\end{array}$ & Placebo & \multicolumn{2}{|l|}{ ADAS-cog } & AD group: ○ & $\begin{array}{l}\mathrm{MCl} \\
\text { group: + }\end{array}$ \\
\hline $\begin{array}{l}\text { Dangour et al. } \\
\text { (2010) }\end{array}$ & $\begin{array}{l}N=867 \\
\text { healthy }\end{array}$ & $\begin{array}{l}\text { I: } 74.7 \pm 2.5 \\
\text { P: } 74.6 \pm 2.7\end{array}$ & 24 months & $\begin{array}{l}200 \mathrm{mg} \text { EPA + } \\
500 \mathrm{mg} \text { DHA/d }\end{array}$ & Placebo & \multicolumn{2}{|c|}{ Extensive NP test battery } & Whole group: ॰ & \\
\hline $\begin{array}{l}\text { Morris et al. } \\
\text { (2005) }\end{array}$ & $\begin{array}{l}N=6185 \\
\text { healthy }\end{array}$ & $\begin{array}{l}\text { 11: } 74.6 \\
\text { I2: } 74.2 \\
\text { I3: } 73.9\end{array}$ & 6 years & Observational & & \multicolumn{2}{|c|}{ Global cognitive score } & \multicolumn{2}{|l|}{ Whole group: + } \\
\hline $\begin{array}{l}\text { Reddy et al. } \\
\text { (2011) }\end{array}$ & $\begin{array}{l}N=27 \\
\text { schizophrenia }\end{array}$ & $18-45$ & 24 weeks & $2 \mathrm{~g} / \mathrm{d}$ EPA & & \multicolumn{2}{|c|}{ Wisconsin Card Sort Test } & \multicolumn{2}{|l|}{ Whole group: + } \\
\hline $\begin{array}{l}\text { Tan et al. } \\
\text { (2012) }\end{array}$ & $\begin{array}{l}N=1575 \\
\text { healthy }\end{array}$ & $67 \pm 9$ & - & \multicolumn{2}{|c|}{$\begin{array}{l}\text { Observational (Red blood cell } \\
\text { EPA + DHA) }\end{array}$} & \multicolumn{2}{|c|}{ Extensive NP test battery } & \multicolumn{2}{|l|}{ Whole group: + } \\
\hline $\begin{array}{l}\text { van de Rest et al. } \\
\text { (2008) }\end{array}$ & $\begin{array}{l}N=302 \\
\text { healthy }\end{array}$ & $\begin{array}{l}\text { I1800: } \\
69.9 \pm 3.4 \\
\text { I400: } 69.5 \pm 3.2 \\
\text { P: } 70.1 \pm 3.7\end{array}$ & 26 weeks & $\begin{array}{l}1800 \mathrm{mg} / \mathrm{d} \\
\text { EPA-DHA } \\
400 \mathrm{mg} / \mathrm{d} \\
\text { EPA-DHA }\end{array}$ & Placebo & \multicolumn{2}{|c|}{ Extensive NP test battery } & Whole group: ॰ & \\
\hline $\begin{array}{l}\text { Witte et al. } \\
\text { (2013) }\end{array}$ & $\begin{array}{l}N=65 \\
\text { healthy }\end{array}$ & $\begin{array}{l}\text { I: } 65 \pm 6.3 \\
\text { P: } 62.9 \pm 6.8\end{array}$ & 26 weeks & $\begin{array}{l}2.2 \mathrm{~g} / \mathrm{d} \\
\text { EPA-DHA }\end{array}$ & Placebo & \multicolumn{2}{|c|}{ Extensive NP test battery } & Whole group: + & \\
\hline
\end{tabular}

AD, Alzheimer's Disease; ADAS-cog, Alzheimer's Disease Assessment Scale, cognitive subscale; DHA, docosahexaenoic acid; EPA, eicosapentaenoic acid; I, age of intervention group; MCl, Mild Cognitive Impairment; MMSE, Mini-Mental State Examination; NP, neuropsychological; P, age of placebo group; +, positive effect on cognition; o, no effect on cognition.

supplementation with $900 \mathrm{mg} / \mathrm{d}$ DHA improved learning and memory function.

Supporting these findings, Pottala et al. (2014) observed in a cross-sectional analysis, that a higher LC-n3-FA intake (indicated by higher proportions of DHA and EPA in the membranes of blood erythrocytes, see Harris and Von Schacky, 2004) was correlated to higher total brain and hippocampal volume in 1111 postmenopausal women. In another cross-sectional study by Tan et al. (2012) in 1575 elderly participants, those with lower DHA had also lower scores on tests of executive function and abstract thinking. Similarly, executive functions could be improved after 24 weeks of supplementary LC-n3-FA intake (2 g EPA/d) in 27 schizophrenic patients in an open-label study (Reddy et al., 2011).

In contrast, other interventional studies in $\mathrm{AD}$ patients (Quinn et al., 2010) or healthy older adults (van de Rest et al., 2008; Dangour et al., 2010) did not support the positive effects of fish oil consumption. These inconsistent results might be explained due to differences in dosage and duration between studies, e.g., that LC-n3-FA intake might not have been sufficient to exert statistically significant effects on cognition. Furthermore studies might differ in intake instructions and cohort characteristics. It has also been noted that not only the amount of LC-n3-FA, but also the overall dietary fat-composition is considerably critical for brain functions (Morris et al., 2005). For example, an unfavorable fat composition might affect cognitive aging more than total fat intake itself (Okereke et al., 2012). Especially saturated fatty acids and trans-fatty acids are supposed to increase the risk of $\mathrm{AD}$ (Hooijmans et al., 2007; Studzinski et al., 2009; Ramassamy and Belkacémi, 2011) and affect cognition (Greenwood and Winocur, 2005), which could be due to decreased Brain-derived neurotrophic factor (BDNF) related synaptic plasticity (Molteni et al., 2002). Thus, it might be speculated that the positive effects of supplementary LC-n3-FA could be masked out by the negative effects of concurrent high saturated- and trans- fatty acid intake. According to the latest Cochrane reviews, it is not yet clear 
that dietary or supplemental LC-n3-FA alter total mortality, combined cardiovascular events or cancers in people with, or at high risk of, cardiovascular disease or in the general population (Hooper et al., 2004). The same stated Sydenham et al. (2012) for LC-n3-FA and dementia. They could not state benefits for cognitive health for older people taking omega-3 supplements. However, none of the mentioned studies reported severe adverse effects of fish or fish oil consumption.

Underlying mechanisms of positive effects of LC-n3-FA on cognition could include a reduction of cardiovascular risk factors, e.g., by improving cerebral blood flow and lowering triacylglycerol levels as found in non-human primates and rats (Katayama et al., 1997; Tsukada et al., 2000; Fotuhi et al., 2009). More direct neuronal effects of LC-n3-FA are e.g., stimulation of neurogenesis and neurite outgrowth (Kawakita et al., 2006) and enhancement of synaptic membrane fluidity (Cansev and Wurtman, 2007). Also, LC-n3-FA have been found to increase the expression of myelin-related proteins (Salvati et al., 2008), which could contribute to improved axonal transmission and thus better neuronal signaling. In addition, LC-n3-FA are thought to upregulate several genes such as Sir2, involved in maintaining synaptic function and plasticity (Wu et al., 2007). A recent study in mice showed an increase of neuroprotectin D-1 (NPD-1) after fish oil treatment (Afshordel et al., 2015). NPD-1 represents a neuroprotective compound that is derived from unesterified DHA (Afshordel et al., 2015).

Moreover, LC-n3-FA play several roles with regard to inflammatory processes. DHA and EPA are capable of competing with arachidonic acid in the production of eicosanoids, which results in the production of biologically less active thromboxans and therefore in a better hemodynamic, vascular tone and inflammation (Mori and Beilin, 2004). LC-n3-FA might also upregulate the expression of antioxidant enzymes and downregulate genes associated with production of reactive oxygen species (ROS), such as peroxisome proliferator-activated receptors gamma (PPAR- $\gamma$; Takahashi et al., 2002; Mori and Beilin, 2004). Additionally, DHA has been implicated in reducing inflammation through fatty acid derivatives such as NPD-1 (Cole et al., 2010) and resolvin species (Kohli and Levy, 2009).

In sum, promising evidence indicates that LC-n3-FA, especially DHA, exert positive effects on brain structure and cognitive functions. Yet, more large-scale RCTs are needed before fish oil intake could be fully recommended as preventive strategy against cognitive decline in the older population.

\section{Polyphenols and their Impact on the Brain}

A further class of substances that is supposed to contribute to the beneficial effects of the Mediterranean Diet (MeDi) is that of polyphenols (Figure 2). Polyphenols are secondary metabolites of plants and characterized by the chemical structure of hydroxyl groups on aromatic rings (Manach et al., 2004). They are quite abundant in our diet and several thousand molecules have been identified to have polyphenol character (Manach et al., 2004). One polyphenol agent that came into research focus is resveratrol (RSV). It occurs naturally in the skin of red grapes, red wine, blueberries, peanuts and Japanese knotweed (Baur and Sinclair, 2006; Baur et al., 2006; Ingram et al., 2006). Another group, the flavonols, are part of the flavonoid family that is found in various fruits, cocoa, beans and the Ginkgo biloba tree (Gómez-Pinilla, 2008). Flavonols contain antiinflammatory properties among several other complex actions (for review, see Gómez-Pinilla, 2008). Although polyphenols are somewhat heterogeneous regarding their chemical properties, they seem to have some effects in common with regard to cardiovascular health and (at least for some polyphenols) antioxidant capacity (Halliwell, 2007; Habauzit and Morand, 2012).

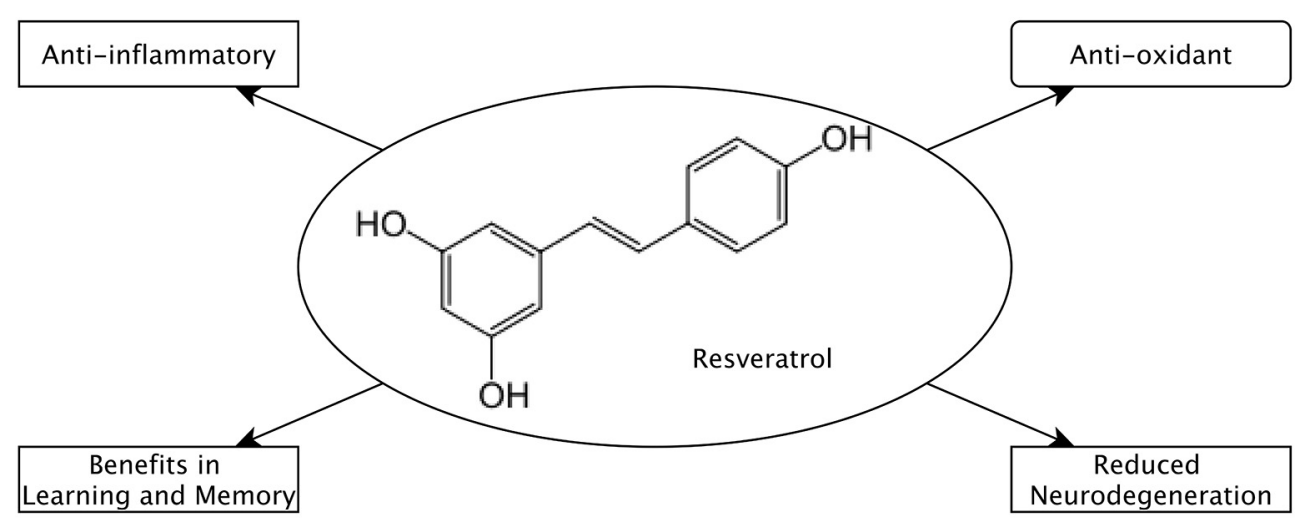

Polyphenols contained in: fruits and vegetables.

Resveratrol especially in grapes, red wine, blueberries, peanuts, Japanese knotweed. 
In vitro, several polyphenols including RSV eliminate a multitude of ROS, including hydroxyl radicals, peroxyl radicals hypochlorous acid and in part superoxide radical (Halliwell, 2007). ROS are considered to be toxic and ROS-induced cell damage is assumed to contribute to the process of aging (Liochev, 2013). In rats, polyphenols have been shown to increase heat-shock protein (HSP) 70 and insulin-like growth factor 1 (IGF-1) expression in the hippocampus, which protects against kainate-induced cell damage and benefits learning and memory performance (Casadesus et al., 2004; Galli et al., 2006). Reduced hippocampal neurodegeneration has also been shown after RSV administration in rodent models for $\mathrm{AD} /$ tauopathies (Kim et al., 2007). In addition, administration of RSV-containing red wine was found to preserve spatial memory, while reducing $A \beta$ neuropathology (Wang et al., 2010). In a non-human primate study, supplementary RSV for 18 months increased spatial memory performance compared to placebo (Dal-Pan et al., 2011).

Considering human studies, there is a considerable heterogeneity in study quality, design and polyphenol formula/dosage (Crichton et al., 2013). See Table 2 for an overview. In a cross-sectional study by Nurk et al. (2009) with 2,031 participants aged 70-74 years from the Hordaland Health Study in Norway, a diet over 1 year high in some flavonol-rich foods, such as chocolate, wine and tea, was associated with better performance in several cognitive abilities in a dose-dependent manner in comparison to a non-consumer group. Only a few placebo-controlled interventional studies are available to date, such as Kennedy et al. (2010). This study assessed the effects of 250 and $500 \mathrm{mg}$ oral RSV on cognitive performance in a RCT crossover study in 22 healthy adults, with the result that even single doses of orally administered RSV can modulate cerebral blood flow variables, measured using MRI (Kennedy et al., 2010). In another study, blueberry supplementation (wild blueberry juice) improved paired associate learning and word list recall, as well as paired associate learning in a small sample of nine older adults after comparison with a matched, placebo-controlled sample (Krikorian et al., 2010). In a double-blind, clinical trial by Small et al. (2014) intake of a pill-based nutraceutical that contained a proprietary formulation of blueberry (including RSV), green tea, carnosine, vitamin D3 and biovin, resulted in significantly increased processing speed of 52 participants compared to placebo $(N=53)$. In an own study with 46 healthy overweight older individuals, a daily intake of $200 \mathrm{mg}$ RSV (in a formula with quercetin) over 26 weeks compared to placebo intake significantly improved memory performance (Witte et al., 2014). In addition, glycated hemoglobin (HbA1c) in peripheral blood was significantly reduced after RSV treatment, and this reduction in $\mathrm{HbAlc}$ correlated with higher functional connectivity of the hippocampus, measured using restingstate functional MRI in the same subjects. Notably, changes in functional connectivity were found to correlate with the observed increases in memory, pointing to ameliorated glucose metabolism as one underlying mechanism of the positive effects of RSV on cognition (Witte et al., 2014). Also, Brickman et al. (2014) reported recently in a randomized study on flavonols with 37 healthy 5069 year old subjects using functional MRI that a diet high in cocoa-flavanol over 3 months enhanced memory function and improved related activation in the dentate gyrus, the hippocampus region characterized by life-long neurogenesis, in comparison to a diet low in cocoa-flavanol.

Both RSV and flavonols could contribute to a better cognitive performance due to their protective effects against oxidative stress, which increases with age and is a risk factor for age-associated cognitive decline. Further possible neuroprotective mechanisms of polyphenols including RSV are reduced mitochondrial dysfunction, glucose toxicity, oxidative damage, and chronic inflammation, by improving glucose metabolism and vascular functions and by activating so-called longevity genes including the sirtuins. For further discussions see

TABLE 2 | Characteristics of studies reporting associations between flavonol or RSV consumption and cognition.

\begin{tabular}{|c|c|c|c|c|c|c|c|c|}
\hline \multirow{3}{*}{$\begin{array}{l}\text { Author (year) } \\
\text { Kennedy et al. (2010) }\end{array}$} & \multirow{2}{*}{\multicolumn{2}{|c|}{$\begin{array}{c}\text { Participants } \\
\text { sample size/age }\end{array}$}} & \multirow{3}{*}{$\begin{array}{l}\text { Duration } \\
\text { Single dose }\end{array}$} & \multirow{2}{*}{\multicolumn{2}{|c|}{ Intervention }} & \multirow{2}{*}{\multicolumn{2}{|c|}{ Measured outcome }} & \multirow{3}{*}{$\begin{array}{c}\begin{array}{c}\text { Results } \\
\text { (Polyphenol) }\end{array} \\
+ \\
+\end{array}$} \\
\hline & & & & & & & & \\
\hline & $N=22$ & Healthy 20.17 y & & 250 mg (RSV) 500 mg (RSV) & Placebo & $\begin{array}{l}\text { Cognitive } \\
\text { task }\end{array}$ & Cerebral blood flow & \\
\hline Krikorian et al. (2010) & $\begin{array}{l}N=9 \\
\text { placebo } \\
N=7\end{array}$ & $\begin{array}{l}\text { Healthy } \\
76.2 \pm 5.2 y\end{array}$ & 12 weeks & \multicolumn{2}{|c|}{ Daily consumption of wild blueberry juice } & $\begin{array}{l}\text { Paired } \\
\text { associate } \\
\text { learning }\end{array}$ & Word list recall & + \\
\hline Nurk et al. (2009) & $N=2031$ & Healthy $70-74$ y & $\begin{array}{l}\text { Cross- } \\
\text { sectional }\end{array}$ & \multicolumn{2}{|c|}{ Observational (Chocolate, Wine, Tea) } & \multicolumn{2}{|c|}{ Extensive NP test battery } & + \\
\hline Small et al. (2014) & $\begin{array}{l}N=52, \\
\text { placebo } \\
N=53\end{array}$ & $\begin{array}{l}\text { Healthy } \\
\text { I: } 72.82 \\
P: 74.34\end{array}$ & 2 months & Pill-based nutraceutical & Placebo & \multicolumn{2}{|c|}{ Extensive NP test battery } & + \\
\hline Witte et al. (2014) & $\begin{array}{l}N=23, \\
\text { Placebo } \\
N=23\end{array}$ & $\begin{array}{l}\text { Healthy, } \\
\text { overweight } \\
\text { I: } 64.8 \pm 6.8 \\
\text { P: } 63.7 \pm 5.3\end{array}$ & 26 weeks & 200 mg/d RSV & Placebo & \multicolumn{2}{|c|}{ Auditory Verbal Learning Test } & + \\
\hline Brickman et al. (2014) & $N=37$ & Healthy 50-69 y & 3 months & High cocoa flavonol-diet & $\begin{array}{l}\text { Low } \\
\text { flavonol- } \\
\text { diet }\end{array}$ & \multicolumn{2}{|c|}{ ModBent task } & + \\
\hline
\end{tabular}

NP, Neuropsychological; P, Age of placebo group; RSV, resveratrol; I, Age of intervention group; $y$, years of age; +, positive effect on cognition; o, no effect on cognition. 
e.g., Calabrese et al. (2008, 2009), Sun et al. (2011), Crichton et al. (2013) and Witte et al. (2014).

\section{Conclusion and Outlook}

A majority of available studies on the topic suggest that consumption of LC-n3-FA with fish or fish oil-supplements and plant polyphenols such as flavonols and RSV exerts positive effects on brain health and cognition in older humans. However, with regard to LC-n3-FA supplementation using fish oil, a final recommendation based on RCTs cannot be drawn, as some studies could not detect a positive effect. Here, more large-scale RCTs that, for example, also control for other fatty acid intake are needed to support a significant benefit of regular supplementary LC-n3-FA intake in maintaining cognitive performance. Considering polyphenols, the evidence based on high-quality RCTs is even less clear, given that only few reliable studies are available to date with different formulas and different duration of the intervention. Yet, those few studies were promising, and the animal literature provided convincing examples that polyphenols are highly potent in activating possible neuroprotective pathways, warranting the initiation of large-scale RCTs in humans on supplementary flavonol or RSV. Moreover, attempts to study in parallel the underlying mechanisms in humans, e.g., using high-resolution MRI, are especially important to further strengthen possible hypotheses that are mainly based on animal research. Future studies also need to address whether intervention-induced changes in LCn3-FA or polyphenol intake relate to changes in fatty acid or polyphenol content at the brain level in humans, e.g., using postmortem techniques.

Besides that, additive or synergistic effects between single dietary components come increasingly into focus. Diet is more than the sum of its components, which is considered in the concept of "food synergy". The assumption is that interactions and synergistic effects of the single food components occur as they are consumed in the framework of a balanced diet (Jacobs et al., 2009). For example, antioxidant nutrients can protect LC-n3-FA from peroxidation to which they are particularly susceptible due to their multiple double bounds (BarbergerGateau, 2014). Also, even though studies on single nutrients

\section{References}

Afshordel, S., Hagl, S., Werner, D., Röhner, N., Kogel, D., Bazan, N. G., et al. (2015). Omega-3 polyunsaturated fatty acids improve mitochondrial dysfunction in brain aging-impact of Bcl-2 and NPD-1 like metabolites. Prostaglandins Leukot. Essent. Fatty Acids 92, 23-31. doi: 10.1016/j.plefa.2014. 05.008

Allès, B., Samieri, C., Féart, C., Jutand, M. A., Laurin, D., and Barberger-Gateau, P. (2012). Dietary patterns: a novel approach to examine the link between nutrition and cognitive function in older individuals. Nutr. Res. Rev. 25, 207-222. doi: 10.1017/s0954422412000133

Bach-Faig, A., Berry, E. M., Lairon, D., Reguant, J., Trichopoulou, A., Dernini, S., et al. (2011). Mediterranean diet pyramid today. Science and cultural updates. Public Health Nutr. 14, 2274-2284. doi: 10.1017/s1368980011002515

Barberger-Gateau, P. (2014). Nutrition and brain aging: how can we move ahead? Eur. J. Clin. Nutr. 68, 1245-1249. doi: 10.1038/ejcn.2014.177 and their interactions might help to explain the beneficial effects of dietary patterns, there is an even greater framework. Yannakoulia et al. (2015) propose not only the additive and synergistic effects of single nutrients or foods, but also add other lifestyle behaviors like physical activity, social support, sharing food, having lengthy meals and post-lunch siestas to that explanatory approach. Regardless of all the modernization processes happening (Bach-Faig et al., 2011), the lifestyle of the Mediterranean countries remains an UNESCO World Cultural Heritage and could thus contribute to a multitude of insights regarding brain functioning and healthy aging (Bach-Faig et al., 2011). First publications of large-scale RCTs, such as VallsPedret et al. (2015) and Ngandu et al. (2015), provide a strong level of scientific evidence for the beneficial effects of the $\mathrm{MeDi}$ on cognitive functions. In addition, ongoing multidomain interventional trials like the Finnish Geriatric Intervention Study to Prevent Cognitive Impairment and Disability (FINGER) will help to gain further insights into the beneficial effects of the MeDi-lifestyle and its components on cognition and brain function. The FINGER-study is a multi-center RCT and includes nutritional guidance, regular exercise, cognitive training and social activity, as well as management of metabolic and vascular risk factors, and might thus shed comprehensively further light on possible mechanisms of how modifiable lifestyle factors could help to maintain cognitive functions throughout age (Kivipelto et al., 2013).

Summing up, LC-n3-FA and polyphenols such as RSV are highly investigated substances in the framework of the MeDi. Even though, more studies are needed to clarify the main effects and their underlying mechanisms, they seem to be promising with regard to their impact on brain structure and function in aging.

\section{Acknowledgments}

This work is supported by the German Research Foundation (CRC1052 Obesity mechanisms) and the European Union, the European Regional Development Fund, and the Free State of Saxony within the framework of the excellence initiative and LIFE-Leipzig Research Center for Civilization Diseases, University of Leipzig. C., et al. (2005). Correlates of regular fish consumption in French elderly community dwellers: data from the three-city study. Eur. J. Clin. Nutr. 59, 817-825. doi: 10.1038/sj.ejen.1602145

Baur, J. A., Pearson, K. J., Price, N. L., Jamieson, H. A., Lerin, C., Kalra, A., et al. (2006). Resveratrol improves health and survival of mice on a high-calorie diet. Nature 444, 337-342. doi: 10.1038/nature05354

Baur, J. A., and Sinclair, D. A. (2006). Therapeutic potential of resveratrol: the in vivo evidence. Nat. Rev. Drug Discov. 5, 493-506. doi: 10.1038/nrd2060

Biessels, G. J., Staekenborg, S., Brunner, E., Brayne, C., and Scheltens, P. (2006). Risk of dementia in diabetes mellitus: a systematic review. Lancet Neurol. 5, 64-74. doi: 10.1016/s1474-4422(05)70284-2

Blondeau, N., Nguemeni, C., Debruyne, D. N., Piens, M., Wu, X., Pan, H., et al. (2009). Subchronic alpha-linolenic acid treatment enhances brain plasticity and exerts an antidepressant effect: a versatile potential therapy for stroke. Neuropsychopharmacology 34, 2548-2559. doi: 10.1038/npp.2009.84 
Brickman, A. M., Khan, U. A., Provenzano, F. A., Yeung, L. K., Suzuki, W., Schroeter, H., et al. (2014). Enhancing dentate gyrus function with dietary flavanols improves cognition in older adults. Nat. Neurosci. 17, 1798-1803. doi: $10.1038 / \mathrm{nn} .3850$

Burdge, G. C. (2006). Metabolism of alpha-linolenic acid in humans. Prostaglandins Leukot. Essent. Fatty Acids 75, 161-168. doi: 10.1016/j.plefa. 2006.05.013

Burdge, G. C., and Calder, P. C. (2005). Conversion of alpha-linolenic acid to longer-chain polyunsaturated fatty acids in human adults. Reprod. Nutr. Dev. 45, 581-597. doi: 10.1051/rnd:2005047

Calabrese, V., Cornelius, C., Mancuso, C., Barone, E., Calafato, S., Bates, T., et al. (2009). Vitagenes, dietary antioxidants and neuroprotection in neurodegenerative diseases. Front. Biosci. (Landmark Ed.) 14, 376-397. doi: 10. $2741 / 3250$

Calabrese, V., Cornelius, C., Mancuso, C., Pennisi, G., Calafato, S., Bellia, F., et al. (2008). Cellular stress response: a novel target for chemoprevention and nutritional neuroprotection in aging, neurodegenerative disorders and longevity. Neurochem. Res. 33, 2444-2471. doi: 10.1007/s11064008-9775-9

Calon, F., Lim, G. P., Yang, F., Morihara, T., Teter, B., Ubeda, O., et al. (2004). Docosahexaenoic acid protects from dendritic pathology in an Alzheimer's disease mouse model. Neuron 43, 633-645. doi: 10.1016/j.neuron. 2004.08 .013

Cansev, M., and Wurtman, R. J. (2007). Chronic administration of docosahexaenoic acid or eicosapentaenoic acid, but not arachidonic acid, alone or in combination with uridine, increases brain phosphatide and synaptic protein levels in gerbils. Neuroscience 148, 421-431. doi: 10.1016/j. neuroscience.2007.06.016

Casadesus, G., Shukitt-Hale, B., Stellwagen, H. M., Zhu, X., Lee, H. G., Smith, M. A., et al. (2004). Modulation of hippocampal plasticity and cognitive behavior by short-term blueberry supplementation in aged rats. Nutr. Neurosci. 7, 309-316. doi: 10.1080/10284150400020482

Chiu, C. C., Su, K. P., Cheng, T. C., Liu, H. C., Chang, C. J., Dewey, M. E., et al. (2008). The effects of omega-3 fatty acids monotherapy in Alzheimer's disease and mild cognitive impairment: a preliminary randomized doubleblind placebo-controlled study. Prog. Neuropsychopharmacol. Biol. Psychiatry 32, 1538-1544. doi: 10.1016/j.pnpbp.2008.05.015

Cole, G. M., Ma, Q. L., and Frautschy, S. A. (2010). Dietary fatty acids and the aging brain. Nutr. Rev. 68(Suppl. 2), S102-S111. doi: 10.1111/j.1753-4887.2010. 00345.x

Couto, E., Boffetta, P., Lagiou, P., Ferrari, P., Buckland, G., Overvad, K., et al. (2011). Mediterranean dietary pattern and cancer risk in the EPIC cohort. $B r$. J. Cancer 104, 1493-1499. doi: 10.1038/bjc.2011.106

Crane, P. K., Walker, R., Hubbard, R. A., Li, G., Nathan, D. M., Zheng, H., et al. (2013). Glucose levels and risk of dementia. N. Engl. J. Med. 369, 540-548. doi: 10.1056/NEJMoa1215740

Crawford, M. A., Bloom, M., Broadhurst, C. L., Schmidt, W. F., Cunnane, S. C., Galli, C., et al. (1999). Evidence for the unique function of docosahexaenoic acid during the evolution of the modern hominid brain. Lipids 34(Suppl.), S39-S47. doi: $10.1007 / \mathrm{bf} 02562227$

Crawford, M. A., Broadhurst, C. L., Guest, M., Nagar, A., Wang, Y., Ghebremeskel, K., et al. (2013). A quantum theory for the irreplaceable role of docosahexaenoic acid in neural cell signalling throughout evolution. Prostaglandins Leukot. Essent. Fatty Acids 88, 5-13. doi: 10.1016/j.plefa.2012.08.005

Crichton, G. E., Bryan, J., and Murphy, K. J. (2013). Dietary antioxidants, cognitive function and dementia-a systematic review. Plant Foods Hum. Nutr. 68, 279-292. doi: 10.1007/s11130-013-0370-0

Dal-Pan, A., Pifferi, F., Marchal, J., Picq, J. L., Aujard, F., and RESTRIKAL Consortium. (2011). Cognitive performances are selectively enhanced during chronic caloric restriction or resveratrol supplementation in a primate. PLoS One 6:e16581. doi: 10.1371/journal.pone.0016581

Dangour, A. D., Allen, E., Elbourne, D., Fasey, N., Fletcher, A. E., Hardy, P., et al. (2010). Effect of 2-y n-3 long-chain polyunsaturated fatty acid supplementation on cognitive function in older people: a randomized, doubleblind, controlled trial. Am. J. Clin. Nutr. 91, 1725-1732. doi: 10.3945/ajcn.2009. 29121

Fotuhi, M., Mohassel, P., and Yaffe, K. (2009). Fish consumption, longchain omega-3 fatty acids and risk of cognitive decline or Alzheimer disease: a complex association. Nat. Clin. Pract. Neurol. 5, 140-152. doi: 10. 1038/ncpneuro1044

Freemantle, E., Vandal, M., Tremblay-Mercier, J., Tremblay, S., Blachère, J.-C., Bégin, M. E., et al. (2006). Omega-3 fatty acids, energy substrates and brain function during aging. Prostaglandins Leukot. Essent. Fatty Acids 75, 213-220. doi: 10.1016/j.plefa.2006.05.011

Freund-Levi, Y., Eriksdotter-Jönhagen, M., Cederholm, T., Basun, H., FaxénIrving, G., Garlind, A., et al. (2006). Omega-3 fatty acid treatment in 174 patients with mild to moderate Alzheimer disease: OmegAD study: a randomized double-blind trial. Arch. Neurol. 63, 1402-1408. doi: 10. 1001/archneur.63.10.1402

Galli, R. L., Bielinski, D. F., Szprengiel, A., Shukitt-Hale, B., and Joseph, J. A. (2006). Blueberry supplemented diet reverses age-related decline in hippocampal HSP70 neuroprotection. Neurobiol. Aging 27, 344-350. doi: 10. 1016/j.neurobiolaging.2005.01.017

Gómez-Pinilla, F. (2008). Brain foods: the effects of nutrients on brain function. Nat. Rev. Neurosci. 9, 568-578. doi: 10.1038/nrn2421

Gotsis, E., Anagnostis, P., Mariolis, A., Vlachou, A., Katsiki, N., and Karagiannis, A. (2015). Health benefits of the Mediterranean diet: an update of research over the last 5 years. Angiology 66, 304-318. doi: 10.1177/0003319714 532169

Greenwood, C. E., and Winocur, G. (2005). High-fat diets, insulin resistance and declining cognitive function. Neurobiol. Aging 26(Suppl. 1), 42-45. doi: 10. 1016/j.neurobiolaging.2005.08.017

Habauzit, V., and Morand, C. (2012). Evidence for a protective effect of polyphenols-containing foods on cardiovascular health: an update for clinicians. Ther. Adv. Chronic Dis. 3, 87-106. doi: 10.1177/2040622311430006

Halliwell, B. (2007). Dietary polyphenols: good, bad, or indifferent for your health? Cardiovasc. Res. 73, 341-347. doi: 10.1016/j.cardiores.2006.10.004

Harris, W. S., and Von Schacky, C. (2004). The Omega-3 index: a new risk factor for death from CHD? Prev. Med. 39, 212-220. doi: 10.1016/j.ypmed.2004. 02.030

Hooijmans, C. R., Rutters, F., Dederen, P. J., Gambarota, G., Veltien, A., van Groen, T., et al. (2007). Changes in cerebral blood volume and amyloid pathology in aged Alzheimer APP/PS1 mice on a docosahexaenoic acid (DHA) diet or cholesterol enriched Typical Western Diet (TWD). Neurobiol. Dis. 28, 16-29. doi: 10.1016/j.nbd.2007.06.007

Hooper, L., Harrison, R. A., Summerbell, C. D., Moore, H., Worthington, H. V., Ness, A., et al. (2004). Omega 3 fatty acids for prevention and treatment of cardiovascular disease. Cochrane Database Syst. Rev. CD003177. doi: 10. 1002/14651858.CD003177.pub2

Hu, N., Yu, J. T., Tan, L., Wang, Y. L., Sun, L., and Tan, L. (2013). Nutrition and the risk of Alzheimer's disease. Biomed. Res. Int. 2013:524820. doi: 10. $1155 / 2013 / 524820$

Ingram, D. K., Zhu, M., Mamczarz, J., Zou, S., Lane, M. A., Roth, G. S., et al. (2006). Calorie restriction mimetics: an emerging research field. Aging Cell 5, 97-108. doi: 10.1111/j.1474-9726.2006.00202.x

Jacobs, D. R. Jr., Gross, M. D., and Tapsell, L. C. (2009). Food synergy: an operational concept for understanding nutrition. Am. J. Clin. Nutr. 89, 1543S-1548S. doi: 10.3945/ajcn.2009.26736B

Katayama, Y., Katsumata, T., Muramatsu, H., Usuda, K., Obo, R., and Terashi, A. (1997). Effect of long-term administration of ethyl eicosapentate (EPA-E) on local cerebral blood flow and glucose utilization in stroke-prone spontaneously hypertensive rats (SHRSP). Brain Res. 761, 300-305. doi: 10.1016/s00068993(97)00350-8

Kaur, N., Chugh, V., and Gupta, A. K. (2014). Essential fatty acids as functional components of foods- a review. J. Food Sci. Technol. 51, 2289-2303. doi: 10 1007/s13197-012-0677-0

Kawakita, E., Hashimoto, M., and Shido, O. (2006). Docosahexaenoic acid promotes neurogenesis in vitro and in vivo. Neuroscience 139, 991-997. doi: 10. 1016/j.neuroscience.2006.01.021

Kennedy, D. O., Wightman, E. L., Reay, J. L., Lietz, G., Okello, E. J., Wilde, A., et al. (2010). Effects of resveratrol on cerebral blood flow variables and cognitive performance in humans: a double-blind, placebo-controlled, crossover investigation. Am. J. Clin. Nutr. 91, 1590-1597. doi: 10.3945/ajcn. 2009.28641

Kerti, L., Witte, A. V., Winkler, A., Grittner, U., Rujescu, D., and Flöel, A. (2013). Higher glucose levels associated with lower memory and reduced hippocampal 
microstructure. Neurology 81, 1746-1752. doi: 10.1212/01.wnl.0000435561. 00234.ee

Keys, A. (1970). Coronary heart disease in seven countries. Circulation 41, 1-198.

Keys, A., Menotti, A., Karvonen, M. J., Aravanis, C., Blackburn, H., Buzina, R., et al. (1986). The diet and 15-year death rate in the seven countries study. Am. J. Epidemiol. 124, 903-915.

Kim, D., Nguyen, M. D., Dobbin, M. M., Fischer, A., Sananbenesi, F., Rodgers, J. T., et al. (2007). SIRT1 deacetylase protects against neurodegeneration in models for Alzheimer's disease and amyotrophic lateral sclerosis. $E M B O$ J. 26, 3169-3179. doi: 10.1038/sj.emboj.7601758

Kivipelto, M., Solomon, A., Ahtiluoto, S., Ngandu, T., Lehtisalo, J., Antikainen, R., et al. (2013). The finnish geriatric intervention study to prevent cognitive impairment and disability (FINGER): study design and progress. Alzheimers Dement. 9, 657-665. doi: 10.1016/j.jalz.2012.09.012

Kohli, P., and Levy, B. D. (2009). Resolvins and protectins: mediating solutions to inflammation. Br. J. Pharmacol. 158, 960-971. doi: 10.1111/j.1476-5381.2009. 00290.x

Krikorian, R., Shidler, M. D., Nash, T. A., Kalt, W., Vinqvist-Tymchuk, M. R., Shukitt-Hale, B., et al. (2010). Blueberry supplementation improves memory in older adults. J. Agric. Food Chem. 58, 3996-4000. doi: 10.1021/jf9029332

Kris-Etherton, P. M., Grieger, J. A., and Etherton, T. D. (2009). Dietary reference intakes for DHA and EPA. Prostaglandins Leukot. Essent. Fatty Acids 81, 99-104. doi: 10.1016/j.plefa.2009.05.011

Lim, G. P., Calon, F., Morihara, T., Yang, F., Teter, B., Ubeda, O., et al. (2005). A diet enriched with the omega-3 fatty acid docosahexaenoic acid reduces amyloid burden in an aged Alzheimer mouse model. J. Neurosci. 25, 3032-3040. doi: 10.1523/jneurosci.4225-04.2005

Liochev, S. I. (2013). Reactive oxygen species and the free radical theory of aging. Free Radic. Biol. Med. 60, 1-4. doi: 10.1016/j.freeradbiomed.2013.02.011

Lopez-Garcia, E., Rodriguez-Artalejo, F., Li, T. Y., Fung, T. T., Li, S., Willett, W. C., et al. (2014). The Mediterranean-style dietary pattern and mortality among men and women with cardiovascular disease. Am. J. Clin. Nutr. 99, 172-180. doi: 10.3945/ajcn.113.068106

Lourida, I., Soni, M., Thompson-Coon, J., Purandare, N., Lang, I. A., Ukoumunne, O. C., et al. (2013). Mediterranean diet, cognitive function and dementia: a systematic review. Epidemiology 24, 479-489. doi: 10.1097/EDE. 0b013e3182944410

Manach, C., Scalbert, A., Morand, C., Rémésy, C., and Jiménez, L. (2004). Polyphenols: food sources and bioavailability. Am. J. Clin. Nutr. 79, 727-747.

Max Rubner-Institut. (2011). "Fisch in der ernährung," in Max Rubner-Institut, ed. H. Rehbein (Hamburg: Max-Rubner-Institut), 1-26.

McCann, J. C., and Ames, B. N. (2005). Is docosahexaenoic acid, an n-3 long-chain polyunsaturated fatty acid, required for development of normal brain function? An overview of evidence from cognitive and behavioral tests in humans and animals. Am. J. Clin. Nutr. 82, 281-295.

McNamara, R. K., and Carlson, S. E. (2006). Role of omega-3 fatty acids in brain development and function: potential implications for the pathogenesis and prevention of psychopathology. Prostaglandins Leukot. Essent. Fatty Acids 75, 329-349. doi: 10.1016/j.plefa.2006.07.010

Molteni, R., Barnard, R. J., Ying, Z., Roberts, C. K., and Gómez-Pinilla, F. (2002). A high-fat, refined sugar diet reduces hippocampal brain-derived neurotrophic factor, neuronal plasticity and learning. Neuroscience 112, 803-814. doi: 10 . 1016/s0306-4522(02)00123-9

Moore, S. C., Yoder, E., Murphy, S., Dutton, G. R., and Spector, A. A. (1991). Astrocytes, not neurons, produce Docosahexaenoic Acid $(22: 60 \omega-3)$ and

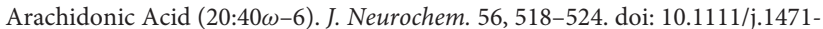
4159.1991.tb08180.x

Mori, T. A., and Beilin, L. J. (2004). Omega-3 fatty acids and inflammation. Curr. Atheroscler. Rep. 6, 461-467. doi: 10.1007/s11883-004-0087-5

Morris, M. C., Evans, D. A., Tangney, C. C., Bienias, J. L., and Wilson, R. S. (2005). Fish consumption and cognitive decline with age in a large community study. Arch. Neurol. 62, 1849-1853. doi: 10.1001/archneur.62.12. noc50161

Ngandu, T., Lehtisalo, J., Solomon, A., Levälahti, E., Ahtiluoto, S., Antikainen, R., et al. (2015). A 2 year multidomain intervention of diet, exercise, cognitive training and vascular risk monitoring versus control to prevent cognitive decline in at-risk elderly people (FINGER): a randomised controlled trial. Lancet 385, 2255-2263. doi: 10.1016/s0140-6736(15)60461-5
Nurk, E., Refsum, H., Drevon, C. A., Tell, G. S., Nygaard, H. A., Engedal, K., et al. (2009). Intake of flavonoid-rich wine, tea and chocolate by elderly men and women is associated with better cognitive test performance. J. Nutr. 139, 120-127. doi: 10.3945/jn.108.095182

Okereke, O. I., Rosner, B. A., Kim, D. H., Kang, J. H., Cook, N. R., Manson, J. E., et al. (2012). Dietary fat types and 4-year cognitive change in communitydwelling older women. Ann. Neurol. 72, 124-134. doi: 10.1002/ana. 23593

Pottala, J. V., Yaffe, K., Robinson, J. G., Espeland, M. A., Wallace, R., and Harris, W. S. (2014). Higher RBC EPA + DHA corresponds with larger total brain and hippocampal volumes: WHIMS-MRI study. Neurology 82, 435-442. doi: 10. 1212/wnl.0000000000000080

Quinn, J. F., Raman, R., Thomas, R. G., Yurko-Mauro, K., Nelson, E. B., Van Dyck, C., et al. (2010). Docosahexaenoic acid supplementation and cognitive decline in Alzheimer disease: a randomized trial. JAMA 304, 1903-1911. doi: 10. 1001/jama.2010.1510

Ramassamy, C., and Belkacémi, A. (2011). Nutrition and alzheimer's disease: is there any connection? Curr. Alzheimer Res. 8, 443-444. doi: 10. 2174/156720511796391890

Reddy, R., Fleet-Michaliszyn, S., Condray, R., Yao, J. K., Keshavan, M. S., and Reddy, R. (2011). Reduction in perseverative errors with adjunctive ethyl-eicosapentaenoic acid in patients with schizophrenia: preliminary study. Prostaglandins Leukot. Essent. Fatty Acids 84, 79-83. doi: 10.1016/j.plefa.2010. 12.001

Sala-Vila, A., and Ros, E. (2011). Mounting evidence that increased consumption of a-linolenic acid, the vegetable n-3 fatty acid, may benefit cardiovascular health. Clin. Lipidol. 6, 365-369. doi: 10.2217/clp.11.36

Salvati, S., Natali, F., Attorri, L., Di Benedetto, R., Leonardi, F., Di Biase, A., et al. (2008). Eicosapentaenoic acid stimulates the expression of myelin proteins in rat brain. J. Neurosci. Res. 86, 776-784. doi: 10.1002/jnr. 21537

Scarmeas, N., Stern, Y., Tang, M. X., Mayeux, R., and Luchsinger, J. A. (2006). Mediterranean diet and risk for Alzheimer's disease. Ann. Neurol. 59, 912-921. doi: 10.1002/ana.20854

Small, B. J., Rawson, K. S., Martin, C., Eisel, S. L., Sanberg, C. D., McEvoy, C. L., et al. (2014). Nutraceutical intervention improves older adults' cognitive functioning. Rejuvenation Res. 17, 27-32. doi: 10.1089/rej.2013.1477

Studzinski, C. M., Li, F., Bruce-Keller, A. J., Fernandez-Kim, S. O., Zhang, L., Weidner, A. M., et al. (2009). Effects of short-term Western diet on cerebral oxidative stress and diabetes related factors in APP x PS1 knock-in mice. J. Neurochem. 108, 860-866. doi: 10.1111/j.1471-4159.2008.05798.x

Su, K. P., Huang, S. Y., Chiu, C. C., and Shen, W. W. (2003). Omega-3 fatty acids in major depressive disorder. A preliminary double-blind, placebo-controlled trial. Eur. Neuropsychopharmacol. 13, 267-271. doi: 10.1016/j.euroneuro.2003. 10.001

Sun, A. Y., Wang, Q., Simonyi, A., and Sun, G. Y. (2011). "Botanical Phenols and Neurodegeneration," in Herbal Medicine: Biomolecular and Clinical Aspects, 2nd Edn. eds Benzie, I. F. F. and S. Wachtel-Galor (Boca Raton, FL: CRC Press), 315-325.

Sydenham, E., Dangour, A. D., and Lim, W. S. (2012). Omega 3 fatty acid for the prevention of cognitive decline and dementia. Cochrane Database Syst. Rev. 6:CD005379. doi: 10.1002/14651858.CD005379.pub3

Takahashi, M., Tsuboyama-Kasaoka, N., Nakatani, T., Ishii, M., Tsutsumi, S., Aburatani, H., et al. (2002). Fish oil feeding alters liver gene expressions to defend against PPARalpha activation and ROS production. Am. J. Physiol. Gastrointest. Liver Physiol. 282, G338-G348. doi: 10.1152/ajpgi. 00376.2001

Tan, Z. S., Harris, W. S., Beiser, A. S., Au, R., Himali, J. J., Debette, S., et al. (2012). Red blood cell omega-3 fatty acid levels and markers of accelerated brain aging. Neurology 78, 658-664. doi: 10.1212/WNL.0b013e31 $8249 f 6 a 9$

Tangney, C. C., Li, H., Wang, Y., Barnes, L., Schneider, J. A., Bennett, D. A., et al. (2014). Relation of DASH- and Mediterranean-like dietary patterns to cognitive decline in older persons. Neurology 83, 1410-1416. doi: 10.1212/wnl. 0000000000000884

Trichopoulou, A., Kouris-Blazos, A., Wahlqvist, M. L., Gnardellis, C., Lagiou, P., Polychronopoulos, E., et al. (1995). Diet and overall survival in elderly people. BMJ 311, 1457-1460. doi: 10.1136/bmj.311.7018.1457 
Tsukada, H., Kakiuchi, T., Fukumoto, D., Nishiyama, S., and Koga, K. (2000). Docosahexaenoic acid (DHA) improves the age-related impairment of the coupling mechanism between neuronal activation and functional cerebral blood flow response: a PET study in conscious monkeys. Brain Res. 862, 180-186. doi: 10.1016/s0006-8993(00)02115-6

Valls-Pedret, C., and Ros, E. (2013). Commentary: Mediterranean diet and cognitive outcomes: epidemiological evidence suggestive, randomized trials needed. Epidemiology 24, 503-506. doi: 10.1097/EDE.0b013e318296bf8e

Valls-Pedret, C., Sala-Vila, A., Serra-Mir, M., Corella, D., de la Torre, R., Martínez-González, M. Á., et al. (2015). Mediterranean diet and age-related cognitive decline: a randomized clinical trial. JAMA Intern. Med. doi: 10. 1001/jamainternmed.2015.1668 [Epub ahead of print].

van den Berg, E., Kloppenborg, R. P., Kessels, R. P., Kappelle, L. J., and Biessels, G. J. (2009). Type 2 diabetes mellitus, hypertension, dyslipidemia and obesity: a systematic comparison of their impact on cognition. Biochim. Biophys. Acta 1792, 470-481. doi: 10.1016/j.bbadis.2008.09.004

van de Rest, O., Berendsen, A. A., Haveman-Nies, A., and de Groot, L. C. (2015). Dietary patterns, cognitive decline and dementia: a systematic review. Adv. Nutr. 6, 154-168. doi: 10.3945/an.114.007617

van de Rest, O., Geleijnse, J. M., Kok, F. J., vvan Staveren, W. A., Dullemeijer, C., Olderikkert, M. G., et al. (2008). Effect of fish oil on cognitive performance in older subjects: a randomized, controlled trial. Neurology 71, 430-438. doi: 10. 1212/01.wnl.0000324268.45138.86

Wang, L., Negreira, A., LaViolette, P., Bakkour, A., Sperling, R. A., and Dickerson, B. C. (2010). Intrinsic interhemispheric hippocampal functional connectivity predicts individual differences in memory performance ability. Hippocampus 20, 345-351. doi: 10.1002/hipo.20771

Willett, W. C., Sacks, F., Trichopoulou, A., Drescher, G., Ferro-Luzzi, A., Helsing, E., et al. (1995). Mediterranean diet pyramid: a cultural model for healthy eating. Am. J. Clin. Nutr. 61, 1402S-1406S.

Witte, A. V., Kerti, L., Hermannstadter, H. M., Fiebach, J. B., Schreiber, S. J., Schuchardt, J. P., et al. (2013). Long-chain omega-3 fatty acids improve brain function and structure in older adults. Cereb. Cortex 24, 3059-3068. doi: 10. 1093/cercor/bht163
Witte, A. V., Kerti, L., Margulies, D. S., and Flöel, A. (2014). Effects of resveratrol on memory performance, hippocampal functional connectivity and glucose metabolism in healthy older adults. J. Neurosci. 34, 7862-7870. doi: 10. 1523/JNEUROSCI.0385-14.2014

World Health Organization. (2009). Interventions on diet and physical activity: what works: summary report. available at: http://apps.who.int/ iris/handle/10665/44140

Wu, A., Ying, Z., and Gomez-Pinilla, F. (2007). Omega-3 fatty acids supplementation restores mechanisms that maintain brain homeostasis in traumatic brain injury. J. Neurotrauma. 24, 1587-1595. doi: 10.1089/neu.2007. 0313

Yannakoulia, M., Kontogianni, M., and Scarmeas, N. (2015). Cognitive health and Mediterranean diet: just diet or lifestyle pattern? Ageing Res. Rev. 20, 74-78. doi: 10.1016/j.arr.2014.10.003

Yates, K. F., Sweat, V., Yau, P. L., Turchiano, M. M., and Convit, A. (2012). Impact of metabolic syndrome on cognition and brain: a selected review of the literature. Arterioscler. Thromb. Vasc. Biol. 32, 2060-2067. doi: 10. 1161/ATVBAHA.112.252759

Yurko-Mauro, K., McCarthy, D., Rom, D., Nelson, E. B., Ryan, A. S., Blackwell, A., et al. (2010). Beneficial effects of docosahexaenoic acid on cognition in agerelated cognitive decline. Alzheimers Dement. 6, 456-464. doi: 10.1016/j.jalz. 2010.01 .013

Conflict of Interest Statement: The authors declare that the research was conducted in the absence of any commercial or financial relationships that could be construed as a potential conflict of interest.

Copyright (C) 2015 Huhn, Kharabian Masouleh, Stumvoll, Villringer and Witte. This is an open-access article distributed under the terms of the Creative Commons Attribution License (CC BY). The use, distribution and reproduction in other forums is permitted, provided the original author(s) or licensor are credited and that the original publication in this journal is cited, in accordance with accepted academic practice. No use, distribution or reproduction is permitted which does not comply with these terms. 